\title{
AC 2011-2390: MOTIVATION MAKES A DIFFERENCE, BUT IS THERE A DIFFERENCE IN MOTIVATION? WHAT INSPIRES WOMEN AND MEN TO STUDY ENGINEERING?
}

\author{
Deborah Kilgore, University of Washington
}

Deborah Kilgore is a Research Scientist in the Center for Engineering Learning \& Teaching at the University of Washington. She has extensive expertise in the learning sciences and qualitative methodologies, and has a particular interest in the experiences of women in engineering.

\section{Sheri Sheppard, Stanford University}

Sheri D. Sheppard, Ph.D., P.E., is professor of Mechanical Engineering at Stanford University. Besides teaching both undergraduate and graduate design-related classes, she conducts research on fracture mechanics and applied finite element analysis, and on how people become engineers. From 1999-2008 she was the Senior Scholar at the Carnegie Foundation for the Advancement of Teaching principally responsible for the Preparations for the Professions Program (PPP) engineering study, the results of which are contained in the report Educating Engineers: Designing for the Future of the Field. From 2003-2009 was co-principal investigator on a National Science Foundation (NSF) grant to form the Center for the Advancement of Engineering Education (CAEE), leading the Academic Pathways Study (APS). Sheri is a fellow of the American Society of Mechanical Engineering (ASME), the American Association for the Advancement of Science (AAAS), and the American Society of Engineering Education (ASEE). Before coming to Stanford University, she held several positions in the automotive industry, including senior research engineer at Ford Motor Company's Scientific Research Lab. Dr. Sheppard's graduate work was done at the University of Michigan.

\section{Cynthia J. Atman, University of Washington}

Cynthia J. Atman is a Professor in Human-Centered Design \& Engineering, founding Director of the Center for Engineering Learning \& Teaching (CELT), Director of the Center for the Advancement of Engineering Education (CAEE) and the inaugural holder of the Mitchell T. \& Lella Blanche Bowie Endowed Chair at the University of Washington. She earned her doctorate in engineering and public policy from Carnegie Mellon University and joined the UW in 1998 after seven years on the faculty at the University of Pittsburgh. Her research focuses on engineering design learning and students as emerging engineering professionals. She is a fellow of AAAS and ASEE, was the 2002 recipient of the ASEE Chester F. Carlson Award for Innovation in Engineering Education, and received the 2009 David B. Thorud Leadership Award, which is given to a UW faculty or staff for demonstrating leadership, innovation, and teamwork.

\section{Debbie Chachra, Franklin W. Olin College of Engineering}

Debbie Chachra is an Associate Professor of Materials Science at Olin College, where she has been involved in the development and evolution of the engineering curriculum since she joined the faculty in 2003. Her current research interests are twofold: as well as her research in biological materials (currently focused on bioderived plastics synthesized by bees), she also researches the engineering student experience, including persistence and migration, differences by gender, and the role of self-efficacy in project-based learning. In 2010, she received an NSF CAREER Award in support of her research on engineering education. 


\section{Motivation makes a difference, but is there a difference in motivation? Some findings from the Academic Pathways Study}

\section{Introduction}

Despite years of research and intervention, women continue to be underrepresented in engineering [1]. In 2008, women comprised $18.4 \%$ of all recipients of an engineering degree [2], continuing an historical trend spanning the last 30 years, during which women's share of engineering degrees has remained stable or even declined. One of the goals of the Academic Pathways Study (APS) of which the present analysis is a part, was to contribute to the ongoing dialogue about underrepresentation in engineering, on both explanatory and remedial topics. The present study discusses some APS findings on gender and motivation to study engineering.

Many scholars have pointed to differences in the ways men and women experience their undergraduate education to suggest potential remedies [3]. One commonly observed phenomenon is stereotype threat, a situation in which a member of a group that is a target of negative stereotypes must perform with the added anxiety that she might confirm those stereotypes [4]. This anxiety has been shown to negatively affect performance; in this way, the individual can reinforce the stereotype.

Stereotype threat for women in engineering consists of two elements: (1) existence and awareness of the negative stereotypes themselves and (2) fear that poor performance will be attributed to being a woman. Several studies have pointed to the stereotype that engineering (and other STEM fields) is a masculine domain [5, 6]. Delisle et al. [5] demonstrated that simply being in the minority reinforced the idea that women did not belong in certain disciplines. Furthermore, women also are aware of a pervasive negative stereotype that they are not good at 
math and science, as this stereotype is reproduced over and over in social interactions with peers, parents, and faculty [4]. One consequence of such a stereotype was shown in ethnographic research conducted by colleagues of the authors, where there was a widespread perception among students at one large public institution that the admissions standards for women into engineering programs is lower than it is for men [7].

The second element of stereotype threat for women in engineering is the fear that if they perform poorly, it will be blamed on their sex [8]. Steele et al. [8] found that women in maledominated disciplines did report more stereotype threat than women in disciplines where they were represented equitably. In an ethnographic study of engineering students in the Academic Pathways Study (APS), Garrison et al. [7] observed a common theme among female students who "went underground" seeking help. These women were reluctant to ask questions in class for fear they would look incompetent or stupid, so they looked for other women outside of class to answer their questions. In addition, Garrison et al. observed that both men and women believed that admissions into engineering was easier for women because of their lower numbers [7]. In another analysis of the interviews used in this paper, Chachra \& Kilgore [9] observed that both women and men expressed a belief that women had an advantage in admissions, getting internships, receiving awards, and getting engineering jobs.

It has been argued that stereotype threat can lead to decreased motivation toward engineering and disengagement, or even leaving the field [10]. For example, Sax [3] found that while both men and women benefited from interactions with faculty, women who felt that faculty dismissed their ideas or did not take them seriously exhibited less interest in graduate school. On the other hand, Delisle et al. [5] did not observe stereotype threat to have a negative effect on what they refer to as autonomous academic motivation. Autonomous academic 
motivation is that driven by positive affective dimensions rather than external rewards or negative internal emotions, and has been found to be associated with higher grades and greater rates of persistence [5].

In the Academic Pathways Study (APS), we observed interesting differences and similarities between men's and women's motivations to study engineering that may or may not be related to stereotype threat, as we will discuss here. In this paper, we will briefly review the APS research methods used to understand gender and academic motivation, present some of what we have learned so far about women's and men's motivations to study engineering, and discuss our findings in light of stereotype threat.

\section{Methods}

The Academic Pathways Study (APS) is a multi-institution, mixed-methods, longitudinal study which examines engineering students' learning and development as they move into, through, and beyond their undergraduate institutions [11]. It is part of the Center for the Advancement of Engineering Education (CAEE), an NSF-funded higher education Center for Learning and Teaching. The APS uses a concurrent triangulation mixed-methods design, in which both qualitative and quantitative methods are employed to collect and analyze data. The integration of results occurs during the interpretation phase [12]. Findings described here come from analysis of two data sources: (1) a broad national survey of over 4,200 undergraduates in 21 institutions [13], (2) qualitative interviews with a subset of 15 students at one institution [14].

\section{National Survey}

The Academic Pathways of People Learning Engineering Survey (APPLES) is a 10-minute online survey designed to characterize the engineering undergraduate experience and factors that 
influence undergraduate persistence in the engineering major and subsequently, the engineering profession. APPLES was administered to engineering students at 21 U.S. engineering colleges and schools in the spring of 2008. Sampling was done by institution using a stratified approach based on institutional characteristics. A total of 4,587 students across 21 institutions participated in the survey. After removing ineligible responses (e.g., from graduate students), the final data set size included 4,266 subjects. The average survey response rate relative to the undergraduate engineering population at participating institutions was 14 percent. Individual school response rates varied from 49 percent at a small institution to 5 percent at a medium-large institution [13].

Among other items, students were asked to report the extent to which they agreed with a number of statements related to motivation. The six motivation constructs and associated items are shown in Table 1.

Table 1. Motivation constructs on the APPLE survey.

\section{Motivation (Financial)}

Engineers are well paid.

Engineers make more money than most other professionals.

An engineering degree will guarantee me a job when I graduate.

\section{Motivation (Parental Influence)}

My parents would disapprove if I chose a major other than engineering.

My parents want me to be an engineer.

\section{Motivation (Social Good)}

Technology plays an important role in solving society's problems.

Engineers have contributed greatly to fixing problems in the world.

Engineering skills can be used for the good of society.

\section{Motivation (Mentor Influence)}

A faculty member, academic advisor, teaching assistant or other university affiliated person has encouraged and/or inspired me to study engineering.

A non-university affiliated mentor has encouraged and/or inspired me to study engineering.

A mentor has introduced me to people and opportunities in engineering.

A mentor has supported my decision to major in engineering.

\section{Motivation (Intrinsic, Psychological)}

Ifeel good when I am doing engineering

I think engineering is fun

I think engineering is interesting

\section{Motivation (Intrinsic, Behavioral)}

I like to build stuff

I like to figure out how things work 


\section{Qualitative Interviews}

Fifteen students at a large, public institution were interviewed in the spring of their senior year (2007). Interviews were semi-structured and open-ended. Questions were designed to elicit students' reflections on their college experience. Students spoke about their motivation to study engineering primarily in response to one question: Are there any aspects of engineering that you particularly like? Follow-up prompts elicited detail about the qualities or specific activities of engineering that students cited. Students spoke about gender and their experience as engineering students in response to three related questions: (1) How has gender played a role in your experience here at the UW? (2) Can you tell me of a particular event, situation, or story in which

you believed your gender played a role in your UW experience? (3) Is there anything about your experience that might have been different for you if you were another gender? Again, follow-up prompts were used to encourage students to provide greater detail.

\section{Select Findings}

Our findings reveal that men and women were more alike than they were different with respect to motivation, as shown in Figure 1. The broad national survey revealed that intrinsic motivations - both the joys of doing and being engineers - were strong for all students. Motivation for social good and financial motivation were not far behind the intrinsic motivators. Students reported being strongly motivated by the belief that as engineers, they could contribute to the improvement of societies, as well as being strongly motivated by the prospect of earning a comfortable living for themselves. Of less significance to these students were mentor or parental influence. 
Intrinsic motivation is different for men and women

In taking a closer look at intrinsic motivation, we can see that some motivators have a different significance for men and women. Intrinsic motivation can be more specifically understood to consist of both psychological and behavioral motivation. Psychological motivation is engineering for its own sake, or the experience of enjoyment inherent in engineering activities. Behavioral motivation is related to the hands-on, action-oriented character of engineering activities [13].

Figure 1. Seniors' Motivation to Study Engineering by Gender Variable (mean scores presented on scale of 0-100; Women n=326; Men n=795; Paired sample t-tests $* * * p<.001, * * p<.01, * p<.05 ;$ Graphic reproduced from [13])

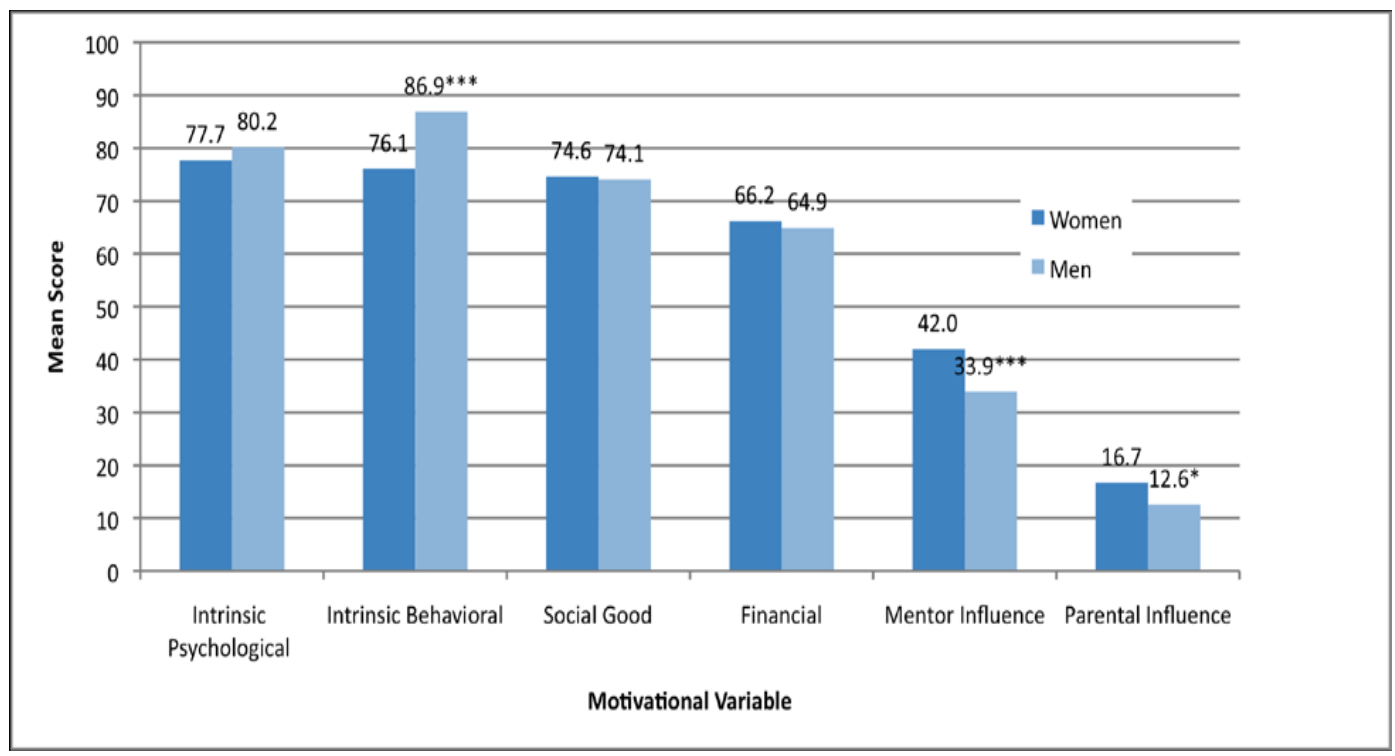

In the broad national sample, behavioral motivation was greater among men than women.

The difference we observed in the broad national sample was reflected in how men and women talked about engineering. For example, Austin, a mechanical engineering major at the large, public university, was not unlike other male students in describing his interest in assembling, disassembling and repairing physical objects. He described his motivation to study engineering: “I've always been interested in, I don't know if — not mechanical systems, but just like putting 
stuff together." In contrast, Lauren, a chemical engineering major at the large public university, was not the only woman to comment on the differences in the ways men and women approach engineering work. She explained,

When we're working on projects and stuff, [men] have a one-track mind where it's like, let's just get through this and then we can go... When I'm in a group, then I sort of have to pay attention to the little details surrounding it, like, oh, what about this, what about this, and maybe we have done this - maybe not get through everything in one sitting as they would like, but then consider more of the big picture sometimes. [9]

\section{Motivation varies by major}

Students' majors also seemed to factor into differences in motivation in the Broader National Sample. For senior women majoring in mechanical engineering (ME), electrical engineering (EE), or aerospace engineering (AE), psychological motivation, behavioral motivation, and social good motivation were of comparable (and high) strength [15]. In contrast, for men in these same three fields, there was a hierarchy: behavioral, followed by psychological, followed by social good. Both men and women majoring in bioscience-related engineering fields (BioX) exhibited comparable (high) levels of psychological, behavioral, and social good motivation, followed by financial motivation - the same pattern as for women in ME, EE, and AE. Nationally, BioX enrolls a significantly higher percentage of women than ME, EE, or AE, so the motivation profiles observed in BioX may reflect the critical mass of women in these majors.

Lauren was majoring in chemical engineering, and described her lab work as "play." 
And, um, got to play with cells and E. coli. And then they were having me optimize some of their concentrations of the solutions they were using to lice their cells, so that was pretty fun.

Similarly, Samantha, a bioengineering major, was enthusiastic about hands-on lab work. There is a fair amount of overlap between chemical engineering and bioengineering at Lauren's and Samantha's university, and representation of women in each major is high (50/50). While it isn't necessarily "traditional" masculine hands on work (e.g., heavy lifting, machining), lab work in these majors is also active and hands-on rather than solely cerebral. With fair representation of women, these majors are imaginable for women and offer the opportunity to engage in a lot of active learning.

\section{Is there a difference in motivation?}

According to our findings, hands-on, action-oriented qualities of engineering activities appear to be of greater significance for men than women when we look across the engineering majors. This may not be especially surprising in light of prior studies that describe a gender gap in "tinkering self-efficacy," the belief that one has the ability to engage in such manual activities as assembling and disassembling, modifying, repairing and so forth [16]. APS qualitative interviews supported the claim that women have less experience than men with respect to manual activities, as several men described specific experiences where they engaged in tinkering, while women typically did not. Silence about an experience does not prove that a person has not had it; however, these comments came in response to inquiries about how a student developed interest and skills in engineering. We would expect students to discuss what they felt were the most relevant experiences. 
For example, John spoke with pride about his ability to repair bicycles,

I literally have taken apart an entire old bike, everything, everything is different, in pieces, and I'm painting the frame, I fixed up -- repaired all the parts and am in the process of putting stuff back together, and still in the process of painting, but for me just kind of working with my hands, I got paint on my hands from yesterday. I just love getting in there and tinkering.

Tinkering is not something women necessarily envision themselves doing, perhaps because they have not had much experience with it. This stereotype can be reinforced by their peers in college. For example, Michael said, “[I]t surprises me, even though it shouldn't, if like a girl has a ton of machining experience." He went on to explain that "not a lot of the girls come in with like shop experience, and I think a lot of the guys do, because I guess that's the kind of thing boys do in high school or something."

It is important to observe that an attraction to the promise of hands-on activity is not necessarily a sort of natural gender-based condition. As we observed earlier, both men and women in bioengineering do hands-on laboratory work and are equally motivated by this element of engineering work. However, this may also apply to the majors where men clearly are drawn by the hands-on aspects of engineering work. When asked to describe the most significant learning experience she had had while in college, Elizabeth described an introductory engineering design course where she experienced hands-on engineering activities for the first time. "Some of the guys they already know this is -- they're like, oh, this is what's going to happen, and when you set the car engine, this is what -- you know, this is how thing works and so on, and then for me, I've never seen them, but it's really cool." She discussed how much fun she had and how the hands-on experiences helped her learning so much. 


\section{Does motivation make a difference?}

We recall from the beginning of this paper that stereotype threat for women in engineering consists of two elements: (1) existence and awareness of the negative stereotypes themselves and (2) fear that poor performance will be attributed to being a woman. The promise of hands-on activity does not necessarily motivate students (in this case, women) who have had little opportunity to envision themselves engaged in it. This can be reinforced when the second condition of stereotype threat has been met. As cited earlier, APS researchers have spoken with women who were reluctant to ask questions in front of their peers and with both women and men who believed that women had an advantage over men and therefore women's accomplishments should be viewed in diminished light.

In this study, we observe women in bioengineering who indeed are engaged in hands-on activity and like it. This reinforces our belief that women's lower motivation with respect to hands-on activity is not a "natural" condition, but rather a learned one. Women who have had the opportunity to participate in hands-on activity appear to enjoy it just as much as men.

In addition to the above revelation, a major like bioengineering that has succeeded in attracting women in representative numbers also may be able to provide clues about how to get beyond stereotype threat. Continued success in the lab can lead to greater self-efficacy with respect to the hands-on activities conducted in the lab. Perhaps the question that must be asked of other engineering majors is: Is there on-going opportunity and encouragement for all students to dig into hands-on projects?

Interestingly and unfortunately, the researchers in Changing the Conversation found that many middle and high school students - both boys and girls - perceived engineering to be sedentary work, and became more interested when the more practical and hands-on aspects of 
engineering were introduced to them. It is important to note that in our study, though there were differences in the strength of behavioral motivation for men and women, most men and women rated it "moderate" or "strong." While introduction to the more active aspects of engineering may draw more students regardless of sex, helping girls to see themselves engaged in these activities may have a particularly positive effect on attracting women into engineering study.

\section{References}

1. Chubin, D., et al., Educating Generation Net-Can US Engineering Woo and Win the Competition for Talent? Journal of Engineering Education, 2008. 97(3): p. 245-257.

2. National Center for Education Statistics, Digest of Education Statistics. 2009, US Department of Education Institute of Education Sciences Washington, DC.

3. Sax, L.J., The gender gap in college. 2008, San Francisco, CA: Jossey-Bass.

4. Aronson, J. and C.M. Steele, Stereotypes and the fragility of academic competence,

motivation, and self-concept, in Handbook of competence and motivation, A.J. Elliot and C.S. Dweck, Editors. 2005, The Guilford Press: London. p. 436-456.

5. Delisle, M.-N., et al., Predicting stereotype endorsement and academic motivation in women in science programs: A longitudinal model. Learning \& Individual Differences, 2009. 19(4): p. 468-475.

6. Male, S.A., M.B. Bush, and K. Murray, Think engineer, think male? European Journal of Engineering Education, 2009. 34(5): p. 455-464.

7. Garrison, L., et al., Cultural models of the admission process in engineering: views on the role of gender, in American Society for Engineering Education Annual Conference \& Exposition. 2007: Honolulu, HI.

8. Steele, J., J. James, and R. Barnett, Learning in a man's world: Examining the perceptions of undergraduate women in male-dominated academic areas. Psychology of Women Quarterly, 2002. 26: p. 46-50.

9. Chachra, D., et al., Being and Becoming: Gender and Identity Formation of Engineering Students, in American Society for Engineering Education Annual Conference. 2008: Pittsburgh, PA.

10. Seymour, E. and N.M. Hewitt, Talk about Leaving: Why Undergraduates Leave the Sciences. 1997, Boulder, CO: Westview Press.

11. Atman, C.J., et al., Enabling Engineering Student Success: The Final Report for the Center for the Advancement of Engineering Education. 2010, San Rafael, CA: Morgan \& Claypool Publishers.

12. Creswell, J.W., et al., Advanced Mixed Methods Research Designs, in Handbook of Mixed Methods in Social and Behavioral Research, A. Tashakkori and C. Teddlie, Editors. 2003, Sage: Thousand Oaks, CA.

13. Sheppard, S., et al., APPLES2-Exploring the engineering student experience: Findings from the Academic Pathways of People Learning Engineering Survey (APPLES). 2010.

14. Kilgore, D., et al., Driven by Passion, Curiosity, Engagement, and Dreams. Findings from the Academic Pathways Study on Undergraduates' Motivations to Study Engineering., in American Educational Research Association. 2009: San Diego, CA.

15. Parikh, S., et al., Does Major Matter? A Look at what Motivates Engineering Students in Different Majors, in American Society for Engineering Education Annual Conference. 2009: Austin, TX.

16. Baker, D., et al., An Intervention to Address Gender Issues in a Course on Design, Engineering, and Technology for Science Educators. Journal of Engineering Education, 2007. 96(3): p. 213-226. 


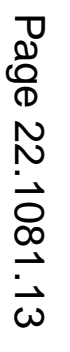

